\title{
AN INITIAL ASSESSMENT OF EXOTIC AND INVASIVE PLANT SPECIES IN SRI LANKA'S FLORA AND THEIR IMPACTS
}

\author{
Carla C Bossard \\ Fulbright fellow, University of Sri Jayewardenepura, \\ Associate Professor, St. Mary's University of California
}

Globally, exotic naturalized plants that behave invasively and occupy wildlands are responsible for greater losses of biodiversity than any other factor except habitat loss and direct exploitation of plant species by people. About $1-2 \%$ of naturalized exotic species become invasive in behavior, infesting and sometimes destroying parks, preserves and refuges. This occurs because the invasive plant species: have no natural enemies or diseases present; spread rapidly due to high reproductive and dispersal capabilities; and out compete native species.

Publications relating to the Sri Lankan flora, and Master's theses available in the library of Dept. of Forestry and Enviromental Science at the University of Sri Jayewardenepura regarding various Sri Lankan biological communities, provide the opportunity for an examination of Sri Lanka's exotic flora and an initial attempt to assess their impact on Sri Lanka's plant communities. Tallying herbs and woody species by life form, habitat preference and origin (indigenous, endemic or exotic) revealed the following. Twenty-five percent of Sri Lanka's flora is exotic species (15.6\% herbacious and $9.4 \%$ woody species) not including cultivated species not known to escape. Herbacious (34.6\%) and liana's / vines $(19.5 \%)$ are the life forms with the highest percentage exotics. The largest proportion of the total number of exotic species is found in disturbed $(22.6 \%)$ and wet forest $(18.4 \%)$ habitats. Amongst herbacious species the proportion of exotics is also high in aquatic habitats $(44.2 \%)$. Certain plant taxa contain species which readily naturalize in Sri Lanka. Four plant families, Fabaceae, Verbeneaceae, Myrtaceae, and Rutaceae contain $>55 \%$ of all woody exotics. The Poaceae, alone account for $28.6 \%$ of all exotic herbs.

Species lists from Masters theses done on two wet zone forest reserves indicate seed banks contain about $30 \%$ exotic species, while mature wet zone forests contain only $5-11 \%$ exotic species. If seed banks contain the seeds of exotic species underwhich the native or mature forest species can not germinate or survive, this would be cause for much concern. It is certainly something that merits further research.

Initial observations in the field were made of \% cover by indigenous + endemic and exotic species along 7 randomly located transects in several different habitat types. Field measurements indicate Sri Lankan wetzone forests are highly resistant to exotics and inhibit potential invasive behavior. Except in young forest gaps (where up to $20 \%$ of cover can be exotic species) almost all cover is indigenous+endemic species. In disturbed lands, wet and low zone grasslands and aquatic habitat (fresh water pond) in Sri Lanka the case was quite different. Greater than $80 \%$ of the cover was exotic species in random transects sampled in these three habitat types.

The total impact of the diverse assemblage of exotic species in Sri Lankan's should be of some concern. The exotics are competing with each other in some habitats which prevents any one of them from taking over and forming a monospecific stand, but the indigenous species are forced out regardless. How widespread this is in other habitats in Sri Lanka merits further research so management recommendations can made.

Proceedings of the Third Annual Forestry Symposium 1997, of the Department of Forestry and Environmental Science, University of Sri Jayewardenepura, Sri Lanka 